\title{
Child with RET proto-oncogene codon 634 mutation
}

\author{
Dilek İnce ${ }^{1}$, Bengü Demirağ ${ }^{2}$, Eda Ataseven ${ }^{1}$, Yeşim Oymak ${ }^{2}$, Hale Tuhan ${ }^{3}$, Osman Zeki \\ Karakuş ${ }^{4}$, Filiz Hazan ${ }^{5}$, Ayhan Abac1 $^{3}$, Erdener Özer ${ }^{6}$, Kamer Mutafoglu ${ }^{7}$, Nur Olgun ${ }^{1}$ \\ Departments of ${ }^{1}$ Pediatric Oncology, ${ }^{3}$ Endocrinology, ${ }^{4}$ Surgery and ${ }^{6}$ Pathology, Dokuz Eylül University Faculty of Medicine; \\ and Departments of ${ }^{2}$ Hematology Oncology and ${ }^{5}$ Medical Genetics, Dr. Behçet Uz Children's Hospital; and Department \\ of ${ }^{7}$ Pediatric Oncology, İzmir University of Economics School of Medicine, İzmir, Turkey. E-mail: dr.dilek.ince@gmail.com \\ Received: 19th December 2016, Revised: 21st February 2017, Accepted: 21st February 2017
}

SUMMARY: İnce D, Demirağ B, Ataseven E, Oymak Y, Tuhan H, Karakuş OZ, Hazan F, Abacı A, Özer E, Mutafoglu K, Olgun N. Child with RET protooncogene codon 634 mutation. Turk J Pediatr 2017; 59: 590-593.

Herein we reported a 7-year-old child with RET proto-oncogene c634 mutation. Her mother had been diagnosed with medullary thyroid carcinoma (MTC), and treated six years ago. Heterozygous mutation of the RET proto-oncogene at c634 had been detected in her mother. Genetic analysis showed the presence of the same mutation in our patient. Thyroid functions were normal. Serum calcitonin level was found mildly elevated. Parathormone (PTH) and carcinoembrionic antigen (CEA) levels were normal. Prophylactic thyroidectomy and sampling of cervical lymph nodes were performed. Histopathologic examination revealed hyperplasia in thyroid $\mathrm{C}$ cells, and reactive lymphadenopathy. The risk of MTC has been reported $100 \%$ through the life of patients with RET protooncogene mutation. It has been reported that particularly patients with c634 mutation have more risk of occurence of metastatic and progressive/recurrent MTC. Prophylactic "thyroidectomy, cervical lymph node dissection" before 5-years-of-age should be considered for these patients.

Key words: medullary C cell hyperplasia, RET proto-oncogene mutation, prophylactic thyroidectomy.

Medullary thyroid carcinoma (MTC) is an uncommon malignancy and the third most common histologic type of thyroid cancer in children and adolescents, as in adults. It arises from the calcitonin $(\mathrm{Ct})$-secreting parafollicular "C" cells. Approximately 20-25\% of MTC presents as part of an autosomal dominant inherited disorder either part of multiple endocrine neoplasia (MEN) 2A and MEN 2B, or familial MTC (FMTC). ${ }^{1-5}$ Childhood MTCs are observed only in familial cases, and their hereditary nature should be investigated. Genetic screening of the DNA alterations allows the early identification of children at risk of developing MTC. The RET proto-oncogene encodes a transmembrane glycoprotein receptor that is expressed in neuroendocrine cells, neural cells, urogenital tract cells and testicular germ cells. It is located in the chromosome 10q11.2, and it has 21 exons. ${ }^{6-10}$ Mutations in the RET proto-oncogene are associated with MEN2 and FMTC. ${ }^{6-10}$ We present herein our experience in the treatment of a child with RET protooncogene codon 634 (c634) mutation.

\section{Case Report}

A 7-year-old girl admitted to our center without complaint. Her medical history was unremarkable. Her mother was 30 years old. Her mother had been diagnosed with MTC, and she was treated six years ago. Heterozygous mutation of the RET proto-oncogene at c634(c.1901 G>T) was detected in her mother. There was no history of any malignancy in mother's family. Her father and 9-year-old sister were healthy. The RET proto-oncogene mutation analysis was negative in the 9-year-old sister The RET proto-oncogene mutation analysis showed heterozygous mutation at c634(c.1901 $\mathrm{G}>\mathrm{T}$ ) in our patient. Physical examination was unremarkable. She had no hypertension, dysmorphic facial feature, marfanoid body habitus or mucosal neuroma. Thyroid function test results were normal; free triiodothyronine 
$4.12 \mathrm{pg} / \mathrm{ml}$ (normal range; NR 2.5-3.9 pg/ $\mathrm{ml}$ ) free thyroxine $0.96 \mathrm{pg} / \mathrm{ml}$ (NR 0.50-1.51 $\mathrm{pg} / \mathrm{ml}$ ), thyroid-stimulating hormone 0.73 $\mu \mathrm{IU} / \mathrm{ml}$ (NR 0.34-5.6 $\mu \mathrm{IU} / \mathrm{ml}$ ). Serum levels of antimycrosomal and antithyroglobulin antibodies were normal [Anti-TPO: $0.2 \mathrm{IU} /$ $\mathrm{ml}(\mathrm{NR}, 0-35 \mathrm{IU} / \mathrm{ml})$, Anti TG $<0.9 \mathrm{IU} / \mathrm{ml}$ (NR 0-40 IU/ml)]. Serum calcitonin level was mildly elevated [37.9 pg/ml, and $26.2 \mathrm{pg} / \mathrm{ml}$ (NR 0-11.5 pg/ml)]. PTH and CEA levels were within normal ranges [PTH 52,4 pg/ml, (NR $12-88 \mathrm{pg} / \mathrm{ml}$ ); CEA $2.21 \mathrm{ng} / \mathrm{ml}$, (NR 0-3.8 $\mathrm{ng} / \mathrm{ml})$ ]. Thyroid ultrasonography revealed no abnormalities. Prophylactic total thyroidectomy and sampling of cervical lymph nodes were performed. Histopathologic examination of thyroid revealed hyperplasia in C cells (Fig. 1 ), and examination of lymph nodes revealed reactive lymphadenopathy. There was no medullary thyroid carcinoma. Her 24-hour urine metanephrines were normal. Participation involved informed consent.

\section{Discussion}

Patients with MTC can present with thyroid nodules, enlarged cervical lymph nodes, diarrhea and flushing episodes, and aggressive cases can be associated with lung, liver and bone metastasis. ${ }^{1-4}$ However, during childhood children at risk who have "index patient/s" in their family can be defined by genetic analysis before MTC occurs, as in our case. It has been reported that $98 \%$ of "index patients" with hereditary $\mathrm{C}$ cell disease have identifiable mutations which are caused by several missense gain-of-function mutations of the RET protooncogene. ${ }^{11}$ Screening for RET proto-oncogene

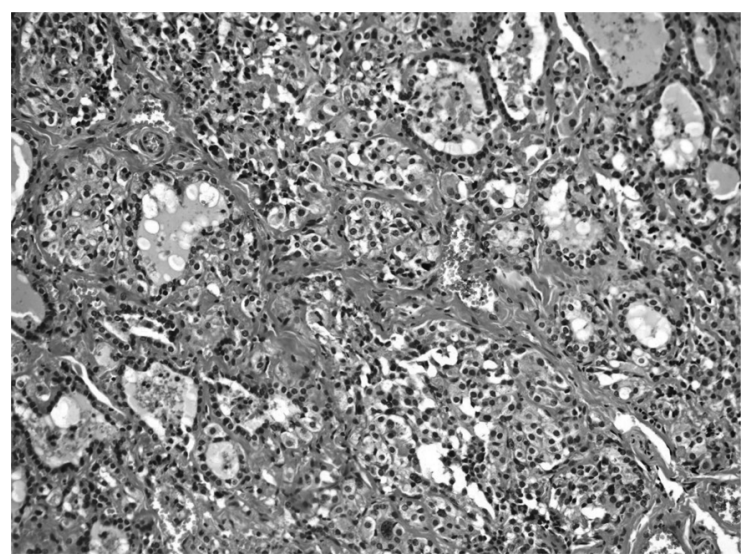

Fig. 1. Thyroid medullary $\mathrm{C}$ cell hyperplasia. mutations is recommended for all sporadic cases. ${ }^{12,13}$ It has been thought that the mother of our patient was a sporadic case who had de novo RET proto-oncogene mutation. Consistent with the autosomal dominant penetrance pattern of RET proto-oncogene mutations, one of her child had no RET mutation whereas the other child (our patient) had the RET mutation.

Hereditary pediatric MTC can be components of MEN2A, MEN2B (syndromic), and FMTC (non-syndromic). MEN 2A comprises MTC, pheochromocytoma (PHEO) and primary hyperparathyroidism (PHPT), it is inherited autosomal dominantly. The most frequent germ line mutations in MEN2A involve the extracellular domain of RET at codons 634, 620 and 618. MTC is present in all affected individuals whereas adrenal PHEs and PHPT occur in only $50 \%$ and $10-30 \%$, respectively. ${ }^{14}$ The risk of PHEO is highest in codon 634 mutations. In the patients with RET mutations in codon 634, PHEO mostly occurs during the fourth or fifth decades. However, it has been rarely reported to occur in children $<10$ years of age. Therefore, it is recommended to provide annual screening of PHEO in children with high risk RET mutations at the age of 5 years. ${ }^{15}$

During childhood RET proto-oncogene mutated gene carriers can be defined in a preclinical stage of MTC. The progression from normal histology of thyroid tissue to MTC through the $\mathrm{C}$ cell hyperplasia occurs over years. Genotype and phenotype correlation is strong. Progression to MTC, clinical presentation and course, and also prognosis are associated with RET proto-oncogene mutations. Risk groups have been defined according to the RET protooncogene mutations. ${ }^{4,11,12}$ The risk classification recommendations of the American Thyroid Association (ATA) are summarized in Table I. $2,11,12$

Timing of the prophylactic surgical approach for $R E T$ proto-oncogene mutated children is also suggested in the ATA guidelines according to the different risk levels of the RET mutation. ${ }^{12,13}$ The timing of prophylactic thyroidectomy is also influenced by the patients age, calcitonin level and family history (Genotype-Age-Calcitonin "GAC" concept). ${ }^{11}$ Prophylactic surgery before the age of 5 (preferably between ages 2 and 4 years) is recommended in patients with codon 634 mutations (ATA risk level C) because of 
Table I. Recommended American Thyroid Association (ATA) Risk Classification and Management of Patients with RET Proto-oncogene Mutations. ${ }^{2,11,12}$

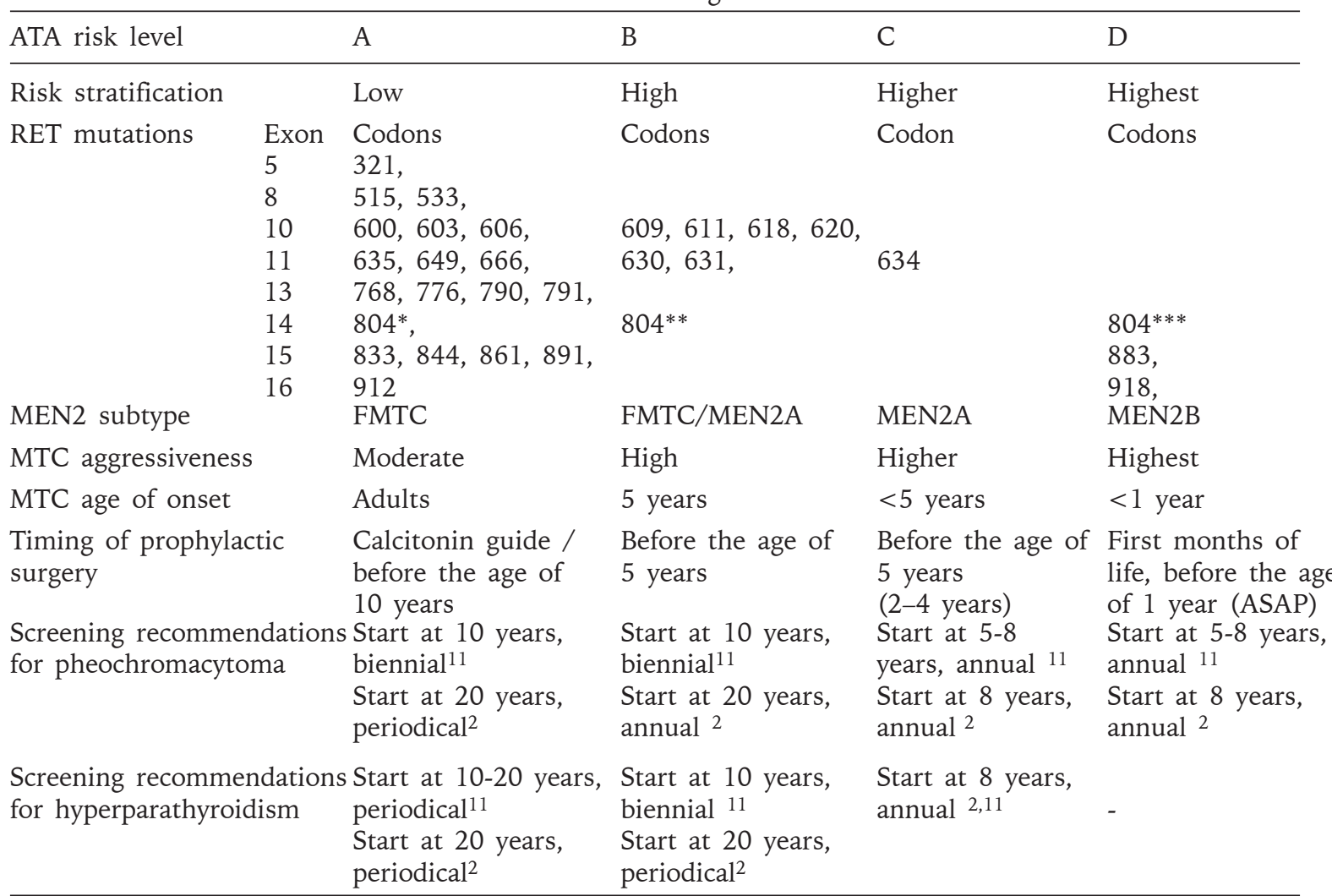

ATA: American Thyroid Association, MEN: multiple endocrine neoplasia, FMTC: familial medullary thyroid carcinoma, ASAP: As soon as possible.

*Single mutation ${ }^{11}$,

** Tandem mutation ${ }^{11}$,

***883 and tandem mutation (804-805; 804-806; 804-904) may have lower malignant potential ${ }^{11}$.

codon-specific progression of early MTC.11-13 However, our case was admitted at 7 years of age and immediate surgery was performed. In such cases surgery should be performed in a center with experienced surgeons. Total thyroidectomy and lymph node sampling were performed in our case. Central (level VI) compartmental dissection is proposed for presence of clinical lymph node metastases, and lateral neck compartmental dissection is proposed for image- or biopsy- positive compartments. ${ }^{12}$ As in our case the central neck dissection can be avoided in ATA risk level C patients with less aggressive family history of MTC and mildly elevated preoperative calcitonin levels, and no evidence of disease on physical examination and radiological imaging. ${ }^{11,12}$ In our case histopathologic examination revealed medullary $\mathrm{C}$ cell hyperplasia and it was thought that mildly elevated preoperative calcitonin level was associated with this finding.

To identify gene carriers, screening for RET proto-oncogene mutation must be performed for all sporadic and familial cases of MTC. The risk of MTC has been reported $100 \%$ through the life of patients who had RET proto-oncogene mutation, and prophylactic thyroidectomy is proposed for these patients. It has been reported that particularly patients with c634 mutation have higher risk for occurrence of metastatic and progressive/recurrent MTC. Therefore, prophylactic thyroidectomy before 5 -years-of-age should be proposed for patients with RET proto-oncogene c634 mutation. Long term follow-up of these patients is required. 


\section{REFERENCES}

1. Viola D, Romei C, Elisei R. Medullary thyroid carcinoma in children. Endocr Dev 2014; 26: 202-213.

2. Raue F, Frank-Raue K. Genotype-phenotype correlation in multiple endocrine neoplasia type 2. Clinics (Sao Paulo) 2012; 67: 69-75

3. Sippel RS, Kunnimalaiyaan M, Chen H. Current management of medullary thyroid cancer. Oncologist 2008; 13: 539-547.

4. Szinnai G, Meier C, Komminoth P, Zumsteg UW. Review of multiple endocrine neoplasia type $2 \mathrm{~A}$ in children: Therapeutic results of early thyroidectomy and prognostic value of codon analysis. Pediatrics 2003; 111: 132-139.

5. Farndon JR, Leight GS, Dilley WG, et al. Familial medullary thyroid carcinoma without associated endocrinopathies: A distinct clinical entity. Br J Surg 1986; 73: 278-281.

6. Donis-Keller H, Dou S, Chi D, et al. Mutations in the RET proto-oncogene are associated with MEN 2A and FMTC. Hum Mol Genet 1993; 2: 851-856.

7. Mulligan LM, Kwok JB, Healey CS et al. Germ-line mutations of the RET proto-oncogene in multiple endocrine neoplasia type 2A. Nature 1993; 363: 458460.

8. Wells SA Jr, Santoro M. Targeting the RET pathway in thyroid cancer. Clin Cancer Res 2009; 15: 7119-7123.
9. Romei C, Pardi E, Cetani F, Elisei R. Genetic and clinical features of multiple endocrine neoplasia types 1 and 2. J Oncol 2012; 2012: 705036.

10. Yip L, Cote GJ, Shapiro SE, et al. Multiple endocrine neoplasia type 2: Evaluation of the genotype-phenotype relationship. Arch Surg 2003; 138: 409-416.

11. Niederle B, Sebag F, Brauckhoff M. Timing and extent of thyroid surgery for gene carriers of hereditary $\mathrm{C}$ cell disease--a consensus statement of the European Society of Endocrine Surgeons (ESES). Langenbecks Arch Surg 2014; 399: 185-197.

12. American Thyroid Association Guidelines Task Force, Kloos RT, Eng C, Evans DB, et al. Medullary thyroid cancer: management guidelines of the American Thyroid Association. Thyroid 2009; 19: 565-612. Erratum in: Thyroid 2009; 19: 1295.

13. Grubbs EG, Waguespack SG, Rich TA, et al. Do the recent American Thyroid Association (ATA) Guidelines accurately guide the timing of prophylactic thyroidectomy in MEN2A? Surgery 2010; 148: 1302 1309.

14. Agarwal S, Agarwal A, Chand G, et al. MEN 2A family--prophylactic thyroidectomy for asymptomatic siblings with positive 634 codon mutation. J Assoc Physicians India. 2012; 60: 127-129.

15. Waguespack SG, Rich TA, Perrier ND, Jimenez C, Cote GJ. Management of medullary thyroid carcinoma and MEN2 syndromes in childhood. Nat Rev Endocrinol 2011; 23; 7: 596-607. 